\title{
Complications after intramedullary nail fixation of pathological versus non- pathological femoral shaft fractures: a retrospective cohort study in 233 patients
}

Chirathit Anusitviwat ${ }^{1 *}$ D, Khanin lamthanaporn ${ }^{1}$, Pakjai Tuntarattanapong ${ }^{1}$, Boonsin Tangtrakulwanich ${ }^{1}$ and Tippawan Liabsuetrakul ${ }^{2}$

\begin{abstract}
Background: Postoperative adverse events after intramedullary nailing have been reported in patients with metastatic pathological and non-pathological femoral fractures. Other consequences to be considered are readmission and reoperation. Few studies have compared the risks of postoperative adverse events, reoperation, and readmission after intramedullary nailing of pathological and non-pathological femur fractures. This study was designed to test the hypothesis that patients with pathological femoral fractures had more adverse events, readmission, and reoperation following surgical fixation than non-pathological femoral fractures.

Methods: This was a retrospective observational cohort study, conducted at an academic medical center in Thailand. The data from patients with femoral shaft fractures undergoing long intramedullary nailing, from June 1 , 2006, to June 30, 2020, were included. Patients who had a pathological fracture from a primary bone tumor, metabolic bone disease, or inadequate/missing information were excluded. Patients with pathological fractures from metastatic bone disease were assigned to be the pathological group whereas those with traumatic fractures were assigned to be the non-pathological group. The primary outcome was the risk of inpatient adverse events as compared between the two groups. The secondary outcome was the risk of consequences after discharge as compared between the two groups. Outcomes were analyzed by using multivariate logistic regression analysis.

Results: The total number of patients was 48 in the pathological fracture group and 185 in the non-pathological group. There were significantly higher rates of surgical and medical adverse events in patients with pathological fractures compared to patients with non-pathological fractures. After adjusting for potential confounding factors in multivariate regression analysis, patients with pathological fractures had higher odds of both adverse surgical (adjusted OR 2.43, $95 \% \mathrm{Cl} 1.15-5.13$ ) and medical adverse events (adjusted OR 2.81, $95 \% \mathrm{Cl}$ 1.13-7.03).
\end{abstract}

Conclusions: Patients with metastatic pathological femoral shaft fractures undergoing intramedullary nailing were more likely to experience postoperative adverse events than patients with non-pathological fractures.

Keywords: Pathological fracture, Femoral shaft, Metastasis, Intramedullary nail

\footnotetext{
*Correspondence: chirathit.a@psu.ac.th

'Department of Orthopedics, Faculty of Medicine, Prince of Songkla

University, 15 Karnjanavanich Road, 90110 Hat Yai, Songkhla, Thailand

Full list of author information is available at the end of the article
}

(c) The Author(s). 2021 Open Access This article is licensed under a Creative Commons Attribution 4.0 International License, which permits use, sharing, adaptation, distribution and reproduction in any medium or format, as long as you give appropriate credit to the original author(s) and the source, provide a link to the Creative Commons licence, and indicate if changes were made. The images or other third party material in this article are included in the article's Creative Commons licence, unless indicated otherwise in a credit line to the material. If material is not included in the article's Creative Commons licence and your intended use is not permitted by statutory regulation or exceeds the permitted use, you will need to obtain permission directly from the copyright holder. To view a copy of this licence, visit http://creativecommons.org/licenses/by/4.0/ The Creative Commons Public Domain Dedication waiver (http://creativecommons.org/publicdomain/zero/1.0/) applies to the data made available in this article, unless otherwise stated in a credit line to the data. 


\section{Introduction}

Femoral shaft fractures are common trauma injuries with high global incidence rates [1]. These fractures usually result from either high or low energy injuries; the latter frequently occur in patients with bones weakened through some pathology [2-4]. Pathological femoral fractures can result from various underlying diseases, such as infection, metabolic bone diseases, or bone tumors. Among bone tumors, metastatic disease is the most frequent malignant neoplasm of the bone, ranging from 25 to $85 \%$, and usually originating from the prostate, breast, lung, kidney, or thyroid [5-8]. The femur is the second most common metastasis site following the vertebra $[9,10]$, with high susceptibility of progression to pathological fractures because the femur is a long, high load-bearing bone $[11,12]$. Pathological fractures of the femur are associated with severe pain, immobilization, and diminished quality of life [7, 13]. Therefore, these patients require prompt surgical intervention to restore their function and relief pain [14-17].

Surgical fixation of metastatic bone disease is principally indicated for pathological femoral fractures [14, 16]. Durable implants and mechanically stable internal fixation need to be considered due to the poor bony union of pathological fractures $[11,18]$. Antegrade intramedullary nailing is an option for treating pathological femoral shaft fractures, since several studies have reported that patients treated with this method had good functional outcomes [19-23]. Although the benefits of internal fixation after a pathological fracture of the femur are known, patients who incurred adverse events following this surgical procedure have been reported [14, 24-27].

Postoperative adverse events reported in patients with femoral fractures showed relatively higher rates of adverse events in pathological fractures than those in nonpathological fractures; even non-pathological fractures have been associated with severe soft tissue injuries and multiple surgical procedures [7, 15, 28]. However, these studies included patients with different characteristics and various surgical procedures, for which the adverse events were not comparable. These adverse events have been reported to increase mortality in patients with pathological fractures after an operation [7, 29]. Few studies have assessed the risk of reoperation and readmission, which are essential for further treatment planning [27]. Hence, this study we analyzed not only adverse events, but also their consequences, including readmission and reoperation. This study aimed to compare the risk of inpatient adverse events and complications after discharge between patients with metastatic pathological and non-pathological femoral fractures undergoing intramedullary nailing. It was hypothesized that patients with pathological femoral fractures had more adverse events, reoperations, and readmissions following surgical fixation.

\section{Methods \\ Study design and sample}

A retrospective study was conducted at Songklanagarind hospital, a tertiary hospital in Thailand. This study was approved by the Institutional Review Board, Faculty of Medicine, Songklanagarind Hospital, Prince of Songkla University (IRB number REC 63-426-11-1). We retrieved the records of patients with femoral fractures undergoing long intramedullary nailing, by using the International Classification of Diseases 9 Procedure (ICD-9): code 79.15 , indicating a closed reduction of fractures with internal fixation of the femur from the Hospital Information System database; from June 1, 2006, to June 30, 2020. Patients aged 20-65 years and diagnosed with femoral shaft fractures were included. Those who had a pathological fracture from a primary bone tumor, metabolic bone disease, or inadequate/missing information were excluded. The sample size was calculated based on the rates of adverse events in patients with pathological and non-pathological fractures of 23 and $7 \%$, respectively. According to a $95 \%$ confidence interval, type II error of $20 \%$, and the ratio of 1:4; at least 50 and 200 patients with pathological and non-pathological fractures were required.

\section{Exposure and control}

Patients who had pathological fractures of the femoral shaft using the ICD-10 code M84.4x were assigned to be the pathological group as the experimental group. Those who had traumatic femoral shaft fractures using the ICD-10 code S72.x and were assigned to be the nonpathological control group.

\section{Outcome measurement and independent variables}

Primary outcomes measured in our study were inpatient postoperative adverse events, which were classified as surgical and medical adverse events as well as reoperation and readmission. Surgical adverse events were defined as surgical site infection that required debridement or prolonged antibiotics, wound dehiscence requiring surgical intervention, hematoma, iatrogenic nerve or arterial injury, or acute anemia necessitating blood transfusions within one day postoperatively. Medical adverse events were defined as sepsis or septic shock, unplanned intubation postoperatively, acute renal failure, pneumonia, urinary tract infection, cerebrovascular disorder, myocardial infarction, venous thromboembolism, or gastrointestinal bleeding. For secondary outcomes, the consequences of their surgical procedure one year after discharge were observed. Readmission due to the progression of their underlying metastatic cancer or 
problems resulting from any adverse event was recorded. Reoperation was defined as an operation performed on a previously operated femur, these was also recorded.

Patients' characteristics, including age, gender, body mass index (BMI), and comorbidities (hypertension, diabetes mellitus, thyroid disease, heart disease, lungs disease, renal disease, liver disease, cerebrovascular disease, rheumatic disorders, hematologic disorders, osteoporosis, and immunodeficiency syndrome) were reviewed and recorded in the data recording form. Preoperative data (duration before surgery, preoperative hematocrit, and platelet), intraoperative data (total blood loss, intraoperative blood transfusion, operative time), and postoperative data (volume of drainage, duration of admission) were also recorded.

\section{Analysis}

The data were entered in EpiData version 3.1 and analyzed using the R software version 4.0.3 (The R Foundation for Statistical Computing, 2020, Vienna, Austria). Patients' characteristics and surgical information between the exposure and control groups were analyzed using unpaired t-test, Wilcoxon rank-sum test, or Chisquare test as appropriate. We compared adverse events, reoperation, and readmission using univariate analysis and multiple logistic regression. Potential variables associated with adverse events, with a p-value less than 0.2 on univariate analysis, were included in the multiple logistic regression models for each outcome using backward stepwise selection. The associations of exposure to all outcomes were measured by the adjusted odds ratios (adjusted OR), with a $95 \%$ confidence interval (CI). Statistical significance was considered as a p-value less than 0.05 .

\section{Results}

There were 56 and 249 patients, respectively, who underwent intramedullary nailing for pathological and non-pathological femoral shaft fractures during the 14year study period. The data of 48 patients with pathological femoral fractures and 185 patients with nonpathological fractures were analyzed for adverse events. Figure 1 shows the flow chart of patient inclusion in this retrospective study. Patient characteristics compared between the two groups are shown in Table 1. Patients with pathological femoral fractures from metastatic bone disease were more likely to be female, had no comorbidity, and were fractured at the proximal location. The mechanism of injury was significantly different when compared between the two groups $(\mathrm{p}<0.001)$. Table 2 shows the number of femoral fractures according to the AO Foundation/Orthopaedic Trauma Association (AO/ OTA) classification system. The majority of fracture type included in this study was simple oblique fracture $(\mathrm{AO} /$
OTA 32-A2); however, some pathological fractures could not be classified as to the AO/OTA system due to severe osteolytic cortical bone destruction. Primary cancers that caused pathological fractures were the breast $(33.3 \%)$ and lung $(33.3 \%)$; which were predominately frequent, followed by thyroid (6.25\%), kidney (6.25\%), prostate $(6.25 \%)$, and the others were nasopharynx, esophagus, liver, or colon. Table 3 shows preoperative, intraoperative, and postoperative parameters. Preoperative hematocrit in patients with pathological fractures were significantly lower than in those with nonpathological fractures $(p=0.031)$. Duration of operative time of fewer than $325 \mathrm{~min}(\mathrm{p}<0.001)$, and volume of drainage $(p=0.003)$ in patients with pathological fractures were significantly higher than those with nonpathological fractures.

The rate of adverse events was $43.7 \%(102 / 233)$, of which $66.7 \%(\mathrm{n}=32)$ were in the pathological fracture group and $37.8 \%(n=70)$ were in the non-pathological fracture group. The rates of surgical and medical adverse events in both groups were $36.9 \%(\mathrm{n}=86)$ and $13.7 \%$ $(n=32)$, respectively (Table 4$)$. There were significantly higher rates of surgical and medical adverse events in patients with pathological fractures compared with patients with non-pathological fractures $(33 \%$ versus $52.1 \%$ and $8.1 \%$ versus $35.4 \%$ ). Acute anemia was the most common adverse surgical event accounting for $47.9 \%$ in pathological fractures and $29.2 \%$ in nonpathological fractures. Septic shock and urinary tract infections in patients with pathological fractures were more common than in the other group. However, there was no incidence of vascular injury, wound dehiscence, or cerebrovascular disorder in either group. Factors associated with adverse events in the final model of multivariate regression analysis are presented in Fig. 2. After adjusting for all potential confounding factors in multivariate regression analysis, patients with pathological fractures had higher odds of overall adverse events (adjusted OR 3.98, $95 \%$ CI 1.85-8.56), adverse surgical events (adjusted OR 2.43, $95 \%$ CI 1.15-5.13), and adverse medical events (adjusted OR 2.81, $95 \%$ CI $1.13-$ 7.03) than in those with the non-pathological fractures. In regard to consequences after discharge, there was an increased risk of readmission in the pathological group (adjusted OR 2.61, 95\% CI 1.00-6.79). On the other hand, the risk of reoperation was not different (adjusted OR $0.23,95 \%$ CI 0.02-2.14).

\section{Discussion}

Rates of adverse events after surgical fixation in patients with metastatic pathological femoral fractures were greater than those with non-pathological femoral fractures after adjusting for other confounding factors. The risk of adverse surgical and medical events in the 


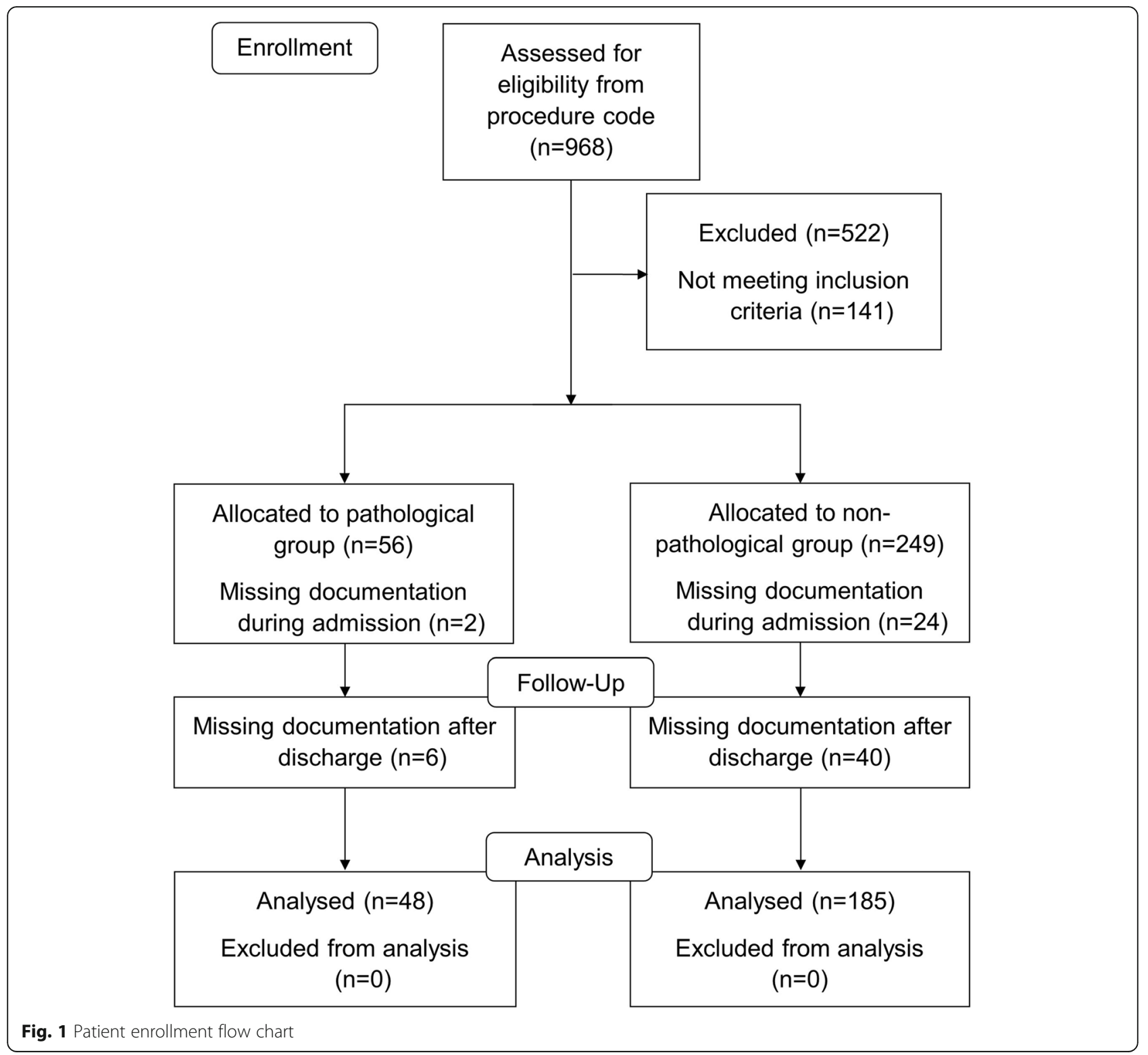

pathological group was two-fold to three-fold higher than the non-pathological group. Patients with pathological fractures were more likely to be readmitted, but less likely to be re-operated on.

Rates of overall adverse events, regardless of the fracture type, in our study were markedly high compared to findings in previous studies, which had different fracture locations and outcome measurements $[3,7,27,29]$. Regarding outcome measurements, other studies did not define acute postoperative anemia as an adverse event, whereas this was the most common adverse event in our study, leading to higher overall adverse event rates [3, 27]. However, if anemia was dismissed, the overall adverse event rates were similar to the previous study [29]. As to fracture locations, Behnke et al. [7] also included fractures at the spine, upper, or lower extremities, not only femur fractures, as in our study. Due to the wide range of fracture locations, the rates of adverse events were probably attenuated.

Acute postoperative anemia was the most frequent adverse surgical event following intramedullary nailing, which was consistent with a previous study that assumed that performing intramedullary nailing was susceptible to bleeding during canal reaming. This resulted in postoperative anemia, which in turn required postoperative blood transfusions [30]. Moreover, significantly higher acute anemia rates have been found in patients with pathological fractures. The explanation is that a high amount of blood loss from passing the intramedullary nail through the hypervascular metastatic femoral lesion, 
Table 1 Patient characteristics compared between the two groups

\begin{tabular}{|c|c|c|c|}
\hline & \multicolumn{2}{|l|}{ Type of Fracture } & \multirow[b]{2}{*}{$p$ value } \\
\hline & $\begin{array}{l}\text { Non-pathological fracture } \\
(n=185), \text { number }(\%)\end{array}$ & $\begin{array}{l}\text { Pathological fracture } \\
(n=48), \text { number }(\%)\end{array}$ & \\
\hline Age (years)* & & & $<0.001$ \\
\hline Median (IQR) & $28(23,45)$ & $60.5(49,67.2)$ & \\
\hline Gender* & & & $<0.001$ \\
\hline Male & $142(76.8)$ & 19 (39.6) & \\
\hline Female & $43(23.2)$ & $29(60.4)$ & \\
\hline Body mass index $\left(\mathrm{kg} / \mathrm{m}^{2}\right)^{*}$ & & & 0.003 \\
\hline Median (IQR) & $22.6(20.4,25.7)$ & $20.1(19.1,21.8)$ & \\
\hline Comorbidities & & & 0.128 \\
\hline At least 1 comorbidity & $50(27)$ & 19 (39.6) & \\
\hline No comorbidity & $135(73)$ & $29(60.4)$ & \\
\hline Location of fracture* & & & $<0.001$ \\
\hline Proximal shaft & $48(25.9)$ & $31(64.6)$ & \\
\hline Midshaft & $128(69.2)$ & $13(27.1)$ & \\
\hline Distal shaft & $9(4.9)$ & $4(8.3)$ & \\
\hline Mechanism of injury* & & & $<0.001$ \\
\hline High injury & $165(89.2)$ & $1(2.1)$ & \\
\hline Low injury & $20(10.8)$ & $13(27.1)$ & \\
\hline No injury & 0 & $34(70.8)$ & \\
\hline
\end{tabular}

IQR interquartile range

*Statistical significance at $p<0.05$

particularly spread from thyroid, prostate, and renal cancer, may prevail the ongoing bleeding with coagulopathic state from high-energy trauma in the non-pathological group [31-33]. Although intraoperative total blood loss and blood transfusions in our study were not different between both groups, the blood loss measured by the volume of drainage was higher in the pathological group, which supported the results of postoperative anemia. No established difference in the incidence of surgical site infection, hematoma, or nerve injuries were found between both groups.

In line with adverse surgical events, risks of adverse medical events were greater in the pathological group. Septic shock and urinary tract infection were common adverse medical events that were higher in the pathological group than that of the non-pathological group. Our results are inconsistent with the findings of a previous study that included impending fractures undergoing

Table 2 Femoral shaft fractures based on the AO/OTA classification system

Femoral shaft fractures, number (\%)

Simple fracture (32-A)

Spiral fracture (32-A1)

0

Oblique fracture (32-A2)

$92(39.4)$

Transverse fracture (32-A3)

$58(24.9)$

Wedge fracture (32-B)

Intact wedge fracture (32-B2)

Fragmentary wedge fracture (32-B3)

Multifragmentary fracture (32-C)

Intact segmental fracture (32-C2)

Fragmentary segmental fracture (32-C3) 
Table 3 Preoperative, intraoperative, and postoperative parameters compared between the two groups

\begin{tabular}{|c|c|c|c|}
\hline & \multicolumn{2}{|l|}{ Type of Fracture } & \multirow[b]{2}{*}{$p$ value } \\
\hline & Non-pathological fracture & Pathological fracture & \\
\hline \multicolumn{4}{|l|}{ Preoperative parameters } \\
\hline Duration before surgery (days) & & & 0.52 \\
\hline Median (IQR) & $8(6,11)$ & $8(5,15.5)$ & \\
\hline Preoperative Hematocrit (\%)* & & & 0.031 \\
\hline Median (IQR) & $33.3(30.1,38.2)$ & $32.3(28.7,34.4)$ & \\
\hline Preoperative Platelet $\left(10^{9} / \mathrm{L}\right)$ & & & 0.131 \\
\hline Median (IQR) & $270(202,366)$ & $311(250.5,382)$ & \\
\hline \multicolumn{4}{|l|}{ Intraoperative parameters } \\
\hline Operative time (minutes)* & & & $<0.001$ \\
\hline Median (IQR) & $355(267,435)$ & $247.5(195,310)$ & \\
\hline Total blood loss (ml) & & & 0.468 \\
\hline Median (IQR) & $350(200,500)$ & $400(200,725)$ & \\
\hline Blood transfusion (ml) & & & 0.06 \\
\hline Median (IQR) & $0(0,198)$ & $0(0,249)$ & \\
\hline \multicolumn{4}{|l|}{ Postoperative parameters } \\
\hline Volume of drainage $(\mathrm{ml})^{*}$ & & & 0.003 \\
\hline Median (IQR) & $80(30,140)$ & $120(51.5,250)$ & \\
\hline Duration of admission (days) & & & 0.875 \\
\hline Median (IQR) & $16(12,21)$ & $15.5(11.8,22.8)$ & \\
\hline
\end{tabular}

$I Q R$ interquartile range

*Statistical significance at $p<0.05$

Table 4 Surgical and medical adverse events compared between the two groups

\begin{tabular}{|c|c|c|c|c|c|}
\hline \multicolumn{4}{|c|}{$\begin{array}{l}\text { Type of Fracture } \\
\end{array}$} & \multirow[b]{2}{*}{ Total } & \multirow[b]{2}{*}{$p$ value } \\
\hline & \multicolumn{2}{|c|}{ Non-pathological fracture, number (\%) } & \multirow{2}{*}{$\begin{array}{l}\text { Pathological fracture, number (\%) } \\
25(52.1)\end{array}$} & & \\
\hline Surgical adverse ever & & $61(33)$ & & $86(36.9)$ & $0.023^{*}$ \\
\hline Surgical site infectic & & $1(0.5)$ & $1(2.1)$ & & 0.370 \\
\hline Hematoma & & $4(2.2)$ & $2(4.2)$ & & 0.606 \\
\hline Acute anemia & & $54(29.2)$ & $23(47.9)$ & & $0.022^{*}$ \\
\hline Nerve injury & & $6(3.2)$ & 0 & & 0.350 \\
\hline Medical adverse ever & & $15(8.1)$ & $17(35.4)$ & $32(13.7)$ & $<0.001^{*}$ \\
\hline Septic shock & & $3(1.6)$ & $4(8.3)$ & & $0.030^{*}$ \\
\hline Acute renal failure & & $3(1.6)$ & $2(4.2)$ & & 0.274 \\
\hline Pneumonia & & $4(2.2)$ & $4(8.3)$ & & 0.059 \\
\hline Urinary tract infecti & ion & $2(1.1)$ & $4(8.3)$ & & $0.017^{*}$ \\
\hline Myocardial infarctio & & 0 & $1(2.1)$ & & 0.206 \\
\hline Gastrointestinal ble & eeding & $1(0.5)$ & $1(2.1)$ & & 0.370 \\
\hline Unplanned intubati & tion & $2(1.1)$ & $1(2.1)$ & & 0.501 \\
\hline Venous thromboem & mbolism & $3(1.6)$ & $3(6.2)$ & & 0.104 \\
\hline
\end{tabular}

*Statistical significance at $p<0.05$ 


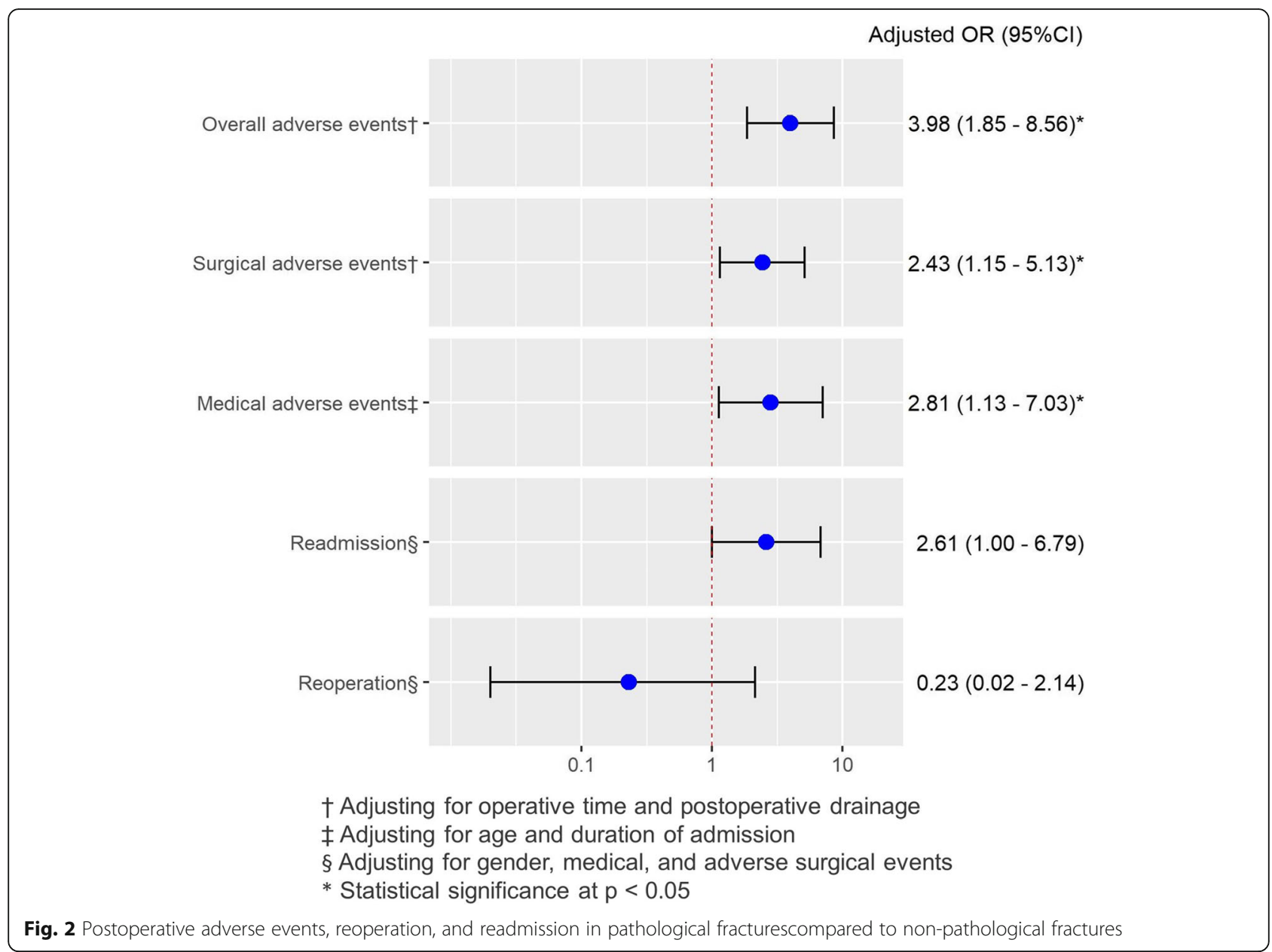

prophylactic stabilization as a control group [27], while our study selected non-pathological fractures. High infection rates in pathological fractures could be explained through old age, low immunity, and the poor baseline status of patients with metastatic bone disease [34]. In addition, patients with pathological fractures required more time for ambulation, which increased the risk of urinary tract infection [35]. Even with slowly progressed ambulation, the incidences of venous thromboembolism events were not significantly increased in patients with pathological fractures because of medical and mechanical prophylaxis given during admission.

In our study, the patients in the pathological group had a readmission rate of more than twice the nonpathological group, which was different from a previous study measuring readmission at only 30 postoperative days [27]. Due to the longer period of data collection in our study, it tended to include more readmission events from adverse events, added with disease progression in the pathological group. Although the previous study did not report on reoperation rates, we attempted to explore this issue, and found similar reoperation rates between the pathological and non-pathological groups. These findings may result from the hypothesis that the pathological group had lower survival rates, particularly in patients experiencing postoperative complications $[15,27]$. Additionally, the surgery goal for pathological fractures was only to improve quality of life; therefore, a second operation was rarely required, with the exception for postoperative complications $[14,16]$. However, the goal of surgical fixation in both traumatic or nonpathological fractures is to provide stability and restore length, alignment, and rotation of the femur to achieve proper bony union. Some patients with this type of fracture were exposed to delayed union or nonunion risk factors; including, smoking history, open fractures, and severe enveloped soft tissue injury [36]. Consequently, they experienced a second surgery to assist in bone healing or to correct malalignment of the femur [37].

To our knowledge, no study has compared adverse events between patients with pathological and nonpathological femoral shaft fractures following surgical fixation. This study does have some limitations. First, this was a single-center study, which may limit the 
generalizability of its findings. Second, the sample size calculation considered the rates of any adverse events between the two groups that may have led to a small sample for specific adverse events. Third, we did not calculate the sample size based on multivariate analysis to identify other associated factors. Finally, this was a retrospective study in which some important data were not recorded.

Recognizing the probability of postoperative adverse events in patients undergoing intramedullary nailing will assist clinicians in providing pertinent information to both patients and their families. Moreover, as a consequence of high adverse surgical and medical events rates, preoperative patient preparation should be heeded, especially reserved blood components. During the postoperative period, hematocrit and vital sign monitoring are suggested, due to the high risks of postoperative anemia and infection. A larger multi-center, prospective study with large sample size is suggested.

\section{Conclusions}

The risks of inpatient postoperative adverse events, especially postoperative anemia, were significantly greater in patients with metastatic pathological femoral shaft fractures than patients with non-pathological fractures undergoing intramedullary nailing after adjusting for potential confounders. Exploring through one-year followup, the risks of readmission in patients with pathological fractures seem higher; however, reoperation rates were not different. Counseling patients about the risk of adverse events along with well-prepared preoperatively patient care should be undertaken.

\section{Abbreviations}

ICD: International Classification of Diseases; BMI: Body mass index; OR: Odds ratio; Cl: Confidence interval; IQR: Interquartile range; AO/OTA: AO

Foundation/Orthopaedic Trauma Association

\section{Acknowledgements}

The authors wish to thank Mr. Andrew Tait, from the International Affairs Department, for his assistance in proofreading the English of this report.

\section{Authors' contributions}

All authors were involved in study conceptualization and study design. CA: data collection, investigation, formal analysis, and writing - original draft. Kl: visualization and validation. PT: Resources. BT: supervision and writing editing manuscript. TL: formal analysis, result interpretation, and writing review and editing manuscript. All authors read and approved the final manuscript for submission.

\section{Funding}

This study did not receive any grant from funding agencies in the public, commercial, or not-for-profit sectors.

Availability of data and materials Not applicable.

\section{Declarations}

\section{Ethics approval and consent to participate}

This study was approved by Institutional Review Board, Faculty of Medicine, Songklanagarind Hospital, Prince of Songkla University (IRB number 63-426 11-1). Requirement for written informed consent by individual participants was waived.

\section{Consent for publication}

Not applicable.

\section{Competing interests}

The authors have no relevant financial or non-financial interests to disclose.

\section{Author details}

${ }^{1}$ Department of Orthopedics, Faculty of Medicine, Prince of Songkla University, 15 Karnjanavanich Road, 90110 Hat Yai, Songkhla, Thailand. ${ }^{2}$ Department of Epidemiology, Faculty of Medicine, Prince of Songkla University, Hat Yai, Songkhla, Thailand.

Received: 2 May 2021 Accepted: 27 July 2021

Published online: 26 August 2021

\section{References}

1. Agarwal-Harding KJ, Meara JG, Greenberg SLM, Hagander LE, Zurakowski D, Dyer GSM. Estimating the global incidence of femoral fracture from road traffic collisions: a literature review. J Bone Joint Surg Am. 2015;97:e31.

2. Enninghorst N, McDougall D, Evans JA, Sisak K, Balogh ZJ. Population-based epidemiology of femur shaft fractures. J Trauma Acute Care Surg. 2013;74: 1516-20.

3. Dodd AC, Salib CG, Lakomkin N, Obremskey WT, Sethi MK. Increased risk of adverse events in management of femur and tibial shaft fractures with plating: An analysis of NSQIP data. J Clin Orthop Trauma. 2016;7:80-5.

4. Mock C, Cherian MN. The global burden of musculoskeletal injuries: challenges and solutions. Clin Orthop Relat Res. 2008:466:2306-16.

5. Kaneko TS, Skinner HB, Keyak JH. Lytic lesions in the femoral neck: Importance of location and evaluation of a novel minimally invasive repair technique. J Orthop Res. 2008;26:1127-32.

6. Ashford RU, Hanna SA, Park DH, Pollock RC, Skinner JA, Briggs TWR, et al. Proximal femoral replacements for metastatic bone disease: financial implications for sarcoma units. Int Orthop. 2010;34:709-13.

7. Behnke NK, Baker DK, Xu S, Niemeier TE, Watson SL, Ponce BA. Risk factors for same-admission mortality after pathologic fracture secondary to metastatic cancer. Support Care Cancer. 2017;25:513-21.

8. Coleman RE. Clinical features of metastatic bone disease and risk of skeletal morbidity. Clin Cancer Res. 2006;12:6243s-9s.

9. Schneiderbauer MM, von Knoch M, Schleck CD, Harmsen WS, Sim FH, Scully SP. Patient survival after hip arthroplasty for metastatic disease of the hip. J Bone Joint Surg Am. 2004;86:1684-9.

10. Hage WD, Aboulafia AJ, Aboulafia DM. Incidence, location, and diagnostic evaluation of metastatic bone disease. Orthop Clin North Am. 2000;31:51528. vii.

11. Fakler JK, Hase F, Böhme J, Josten C. Safety aspects in surgical treatment of pathological fractures of the proximal femur - modular endoprosthetic replacement vs. intramedullary nailing. Patient Saf Surg. 2013;7:37.

12. Wedin R, Bauer HCF. Surgical treatment of skeletal metastatic lesions of the proximal femur: endoprosthesis or reconstruction nail? J Bone Joint Surg Br. 2005;87:1653-7.

13. Rodrigues L, Cornelis FH, Reina N, Chevret S.Prevention of pathological fracture of the proximal femur: A systematic review of surgical and percutaneous image-guided techniques used in interventional oncology. Medicina (Kaunas).2019;55.

14. Ward WG, Holsenbeck S, Dorey FJ, Spang J, Howe D.Metastatic disease of the femur: surgical treatment.Clin Orthop Relat Res.2003;S230-244.

15. Hill T, D'Alessandro P, Murray K, Yates P. Prognostic factors following pathological fractures. ANZ J Surg. 2015:85:159-63.

16. Ruggieri P, Mavrogenis AF, Casadei R, Errani C, Angelini A, Calabrò T, et al. Protocol of surgical treatment of long bone pathological fractures. Injury. 2010:41:1161-7. 
17. Chandrasekar CR, Grimer RJ, Carter SR, Tillman RM, Abudu A, Buckley L. Modular endoprosthetic replacement for tumours of the proximal femur. J Bone Joint Surg Br. 2009;91:108-12.

18. Gainor BJ, Buchert P.Fracture healing in metastatic bone disease.Clin Orthop Relat Res.1983;297-302.

19. Moon B, Lin P, Satcher R, Bird J, Lewis V. Intramedullary nailing of femoral diaphyseal metastases: Is it necessary to protect the femoral neck? Clin Orthop Relat Res. 2015;473:1499-502.

20. Arvinius C, Parra JLC, Mateo LS, Maroto RG, Borrego AF. Stern LL-D. Benefits of early intramedullary nailing in femoral metastases. Int Orthop. 2014;38: 129-32.

21. Samsani SR, Panikkar V, Venu KM, Georgiannos D, Calthorpe D. Breast cancer bone metastasis in femur: surgical considerations and reconstruction with Long Gamma Nail. Eur J Surg Oncol. 2004;30:993-7.

22. Weber KL, O'Connor Ml.Operative treatment of long bone metastases: focus on the femur.Clin Orthop Relat Res.2003:S276-278.

23. Weber KL, Randall RL, Grossman S, Parvizi J. Management of lower-extremity bone metastasis. J Bone Joint Surg Am. 2006;88(Suppl 4):11-9.

24. Teixeira LEM, Miranda RH, Ghedini DF, Aguilar RB, Novais ENV de Abreu e Silva GM, et al.early complications in the orthopedic treatment of bone metastases. Rev Bras Ortop 2015;44:519-23.

25. Groot OQ, Ogink PT, Janssen SJ, Paulino Pereira NR, Lozano-Calderon S, Raskin $\mathrm{K}$, et al. High risk of venous thromboembolism after surgery for long Bone metastases: A retrospective study of 682 patients. Clin Orthop Relat Res. 2018;476:2052-61.

26. Peterson JR, Decilveo AP, O'Connor IT, Golub I, Wittig JC. What are the functional results and complications with long stem hemiarthroplasty in patients with metastases to the proximal femur? Clin Orthop Relat Res. 2017; $475: 745-56$

27. McLynn RP, Ondeck NT, Grauer JN, Lindskog DM. What is the adverse event profile after prophylactic treatment of femoral shaft or distal femur metastases? Clin Orthop Relat Res. 2018;476:2381-8.

28. Minhas SV, Ho BS, Switaj PJ, Ochenjele G, Kadakia AR. A comparison of 30day complications following plate fixation versus intramedullary nailing of closed extra-articular tibia fractures. Injury. 2015:46:734-9.

29. Ristevski B, Jenkinson RJ, Stephen DJG, Finkelstein J, Schemitsch EH, McKee $M D$, et al. Mortality and complications following stabilization of femoral metastatic lesions: a population-based study of regional variation and outcome. Can J Surg. 2009;52:302-8.

30. Forster MC, Aster AS, Ahmed S. Reaming during anterograde femoral nailing: is it worth it? Injury. 2005:36:445-9.

31. Rossaint R, Bouillon B, Cerny V, Coats TJ, Duranteau J, Fernández-Mondéjar E, et al. Management of bleeding following major trauma: an updated European guideline. Crit Care. 2010;14:R52

32. Scolaro JA, Lackman RD. Surgical management of metastatic long bone fractures: principles and techniques. J Am Acad Orthop Surg. 2014;22: 90-100.

33. Pazionis TJC, Papanastassiou ID, Maybody M, Healey JH. Embolization of hypervascular bone metastases reduces intraoperative blood loss: A casecontrol Study. Clin Orthop Relat Res. 2014;472:3179-87.

34. Rolston KVI. Infections in cancer patients with solid tumors: A review. Infect Dis Ther. 2017;6:69-83.

35. Rogers MA, Fries BE, Kaufman SR, Mody L, McMahon LF, Saint S. Mobility and other predictors of hospitalization for urinary tract infection: a retrospective cohort study. BMC Geriatr. 2008;8:31.

36. Taitsman LA, Lynch JR, Agel J, Barei DP, Nork SE. Risk factors for femoral nonunion after femoral shaft fracture. J Trauma. 2009;67:1389-92.

37. Lynch JR, Taitsman LA, Barei DP, Nork SE. Femoral Nonunion: Risk Factors and Treatment Options. JAAOS - Journal of the American Academy of Orthopaedic Surgeons. 2008;16:88-97.

\section{Publisher's Note}

Springer Nature remains neutral with regard to jurisdictional claims in published maps and institutional affiliations.

Ready to submit your research? Choose BMC and benefit from:

- fast, convenient online submission

- thorough peer review by experienced researchers in your field

- rapid publication on acceptance

- support for research data, including large and complex data types

- gold Open Access which fosters wider collaboration and increased citations

- maximum visibility for your research: over $100 \mathrm{M}$ website views per year

At BMC, research is always in progress.

Learn more biomedcentral.com/submissions 